\title{
A VIDA COM FARDA* \\ A vestimenta policial como relato institucional em disputa
}

\section{Mariana Sirimarco}

Tradução de Gértea Oliveira e Ivone Pereira Lima

I

Toda instituição constrói relatos que a sustentam - narrativas que encenam discursos, vivências e valorizações e que a permitem pensar a si mesma como grupo social e como instituição. Trata-se de estabelecer diretrizes que pretendem guiar os próprios integrantes ou os de fora em busca de uma determinada apreensão da realidade social. Os relatos institucionais condensam significados: contam uma história que todos julgam compartilhada, instituem uma gama de sentidos que deverão ser traduzidos em entendimentos totais. Dizem quem e como se é, tanto aos pertencentes como aos não pertencentes ao grupo.

* Uniforme no texto original em espanhol. A intenção da autora foi usar o vocábulo como recurso estilístico para exprimir seu duplo sentido.

Artigo recebido em 29/03/2011

Aprovado em 14/12/2012
Alguns autores sustentaram que a narrativização estabelece as margens para o funcionamento cognitivo, a construção de uma versão da realidade cuja aceitação é mais governada pela convenção e pela "necessidade narrativa" do que pela verificação empírica e pela necessidade lógica. Com base nesse ponto de vista, a narrativização pertence ao plano da interpretação dos fatos, e não da sua descrição; é uma forma não só de representar como também de constituir a realidade (Bruner, 1991; Ochs e Capps, 1996).

O relato institucional opera, nesse sentido, como uma matriz que organiza experiências outorgando-lhes significação, criando e afirmando identidades coletivas, relações sociais, conhecimentos e crenças (Spivak L'Hoste, 2010). Como instâncias de representação da realidade social e de ação sobre ela, relato e instituição tornam-se inseparáveis. Para existir como tal, a instituição deve narrar-se, isto é, reproduzir-se. Nenhum fato é viável enquanto não for categorizado (Bruner, 1998; Lewkowicz, 2004). 
Não se deve acreditar, no entanto, que a categorização (ou depuração) desse entendimento ancore-se somente em uma semantização verbalizada. O relato institucional, como narrativa, integra variadas formas comunicativas, sem ignorar o registro visual ou o corporal. O discurso quase nunca é monomodal: sua constituição apela para uma diversidade de elementos (Ochs e Capps, 1996).

Vários são os relatos - retóricos, icônicos, corporais - com os quais a instituição policial escolheu pensar-se. Vários também são os significados com que ela se sentiu confortavelmente representada. $\mathrm{O}$ sacrifício, a abnegação (os heróis caídos em cumprimento do dever), o heroísmo, a periculosidade e o arrojo (o trabalho policial como luta contra o crime) são só alguns dos mais visíveis. Esses discursos tingem de significação e legitimidade a atividade policial: por meio dessas imagens, o policial se apresenta à sociedade ao mesmo tempo que se apresenta a si mesmo.

Esses relatos institucionais não constituem estruturas semânticas fechadas, capazes de orientar o entendimento dos membros em sentidos sempre iguais e sempre regulados. Um relato não é uma peça unívoca, embora essa seja sua pretensão. Pelo contrário, trata-se de um texto social que, apesar de compactar sentidos, eludir certas circunstâncias e ressaltar certos elementos, não consegue camuflar o entrelaçamento de vozes e tradições que o compõem. Procura-se fazer do relato institucional um discurso compartilhado; entretanto, trata-se de um espaço em disputa.

Isso ocorre porque obedece a um simples fato. Um relato pode apresentar-se como uma estrutura com pretensões de consubstanciar um fato semântico. No entanto, a intencionalidade de tal vontade não condiciona, necessariamente, a sua leitura. A compreensão de um relato - sua aceitação, sua assimilação, sua reprodução - depende, em última instância, de leituras concretas e individuais. As pessoas de dentro e de fora da instituição são as que, com suas interpretações, suas associações, suas sensibilidades e suas vivências, "leem", de modo específico, um discurso determinado. Essas leituras, sejam elas afins ou antagônicas, agregam camadas ao relato que se constrói em uma relação de diálogo: um relato institucional é assim considerado por interpelar sentidos capazes de se tornar sensíveis aos atores envolvidos.

Convém esclarecer, neste ponto, que falar de uma instituição não implica fazer referência a uma estrutura existente por si só. Giddens (1984) afirma que a estrutura institucional não existe como uma entidade fora dos indivíduos que a compõem, mas sim como uma encarnação de suas práticas. $\mathrm{O}$ traço institucional - enfatiza - não se encontra fora desses sujeitos, mas sim justamente neles mesmos. Trata-se, nas palavras de Lewkowicz (2008), não tanto de um laço, mas do modo como os indivíduos que formam um grupo são instituídos por e para esse laço.

É atendendo a essas argumentações que falo da instituição policial, aludindo a esses traços que, encarnados no indivíduo - assentados na totalidade dos policiais, mesmo talvez distintamente -, constituem a expressão de um sentir coletivo. Minha proposta é sustentar que esse sentir coletivo nunca é homogêneo e que, por isso, o relato institucional que pretende dar-lhe forma não pode ser senão uma arena disputada.

É justamente nessas leituras, nesses acordos ou nessas respostas, que o relato institucional se afirma ou cambaleia, sustenta-se no tempo ou eventualmente muda. O relato institucional, é claro, dá conta de uma narrativa que pode ser considerada dominante (embora não necessariamente acatada), cunhada por pessoas ou setores que conseguiram pôr em circulação, com maior êxito, um certo modo de compreensão da realidade. Tal relato dá conta também de um momento político-social; além disso, seu posicionamento está em relação direta com esse contexto. Tal relato é, de qualquer forma, a fotografia de um certo momento. Se nos aproximarmos dela, porém, o que parece uma fixação estática da realidade torna-se, na verdade, um processo em movimento e em tensão.

Este trabalho pretende abordar um dos relatos institucionais mais estimados para a força policial: a farda como investidura. A escolha de tal figura radica-se na valorização que ela adquire para a corporação policial. A partir dos níveis iniciais da trajetória profissional, normativas, regulamentos e superiores esforçam-se, como veremos, para decodificar a farda em termos de honra e fidalguia. Seu uso e seu 
cuidado devem tender à perfeição; a negligência em sua apresentação ou em sua manutenção é imediatamente meritória de sanção disciplinar:

$\mathrm{O}$ ato de usar a farda com falta de botôes (ou botôes desabotoados), de insígnias, de atributos, de emblemas ou distintivos de grau, ou com as correias, calçados e outras peças que não estejam em perfeitas condições de asseio e conservação é falta de disciplina que todos os superiores devem reprimir inflexivelmente (Argentina, 1947, cap. 1, art. 7).

A construção da farda nesses termos a transforma em um relato institucional, pois em torno dos símbolos que encarna se constrói um entendimento tanto do indivíduo que a veste como do grupo ao qual ele pertence. É nessa veiculação de entendimentos não só profissionais como também morais que reside seu sentido de relato. Debruçar-se sobre essa figura narrativa - sobre os elementos que tanto a constroem quanto a tensionam - é debruçar-se, consequentemente, sobre os significados com os quais a instituição policial pretende apresentar-se.

A persecução de tal objetivo requer uma metodologia que possa dar conta não só do dever ser alentado a partir da instituição policial (leis, regulamentos, normativas) como também, em sua maioria, das práticas dos sujeitos envolvidos. $\mathrm{O}$ presente estudo se baseia em onze anos de trabalho de campo em instituições policiais, ${ }^{1}$ nas quais, a partir do método etnográfico, entrei em estreita vinculação com pessoal de diversas funçōes e hierarquias da polícia. Aproximar-se dos entendimentos e valorizações que constituem o sentir policial implica ratificar a pertinência de uma abordagem de análise que privilegie tanto o que foi dito como o que foi posto em ação. $O$ presente trabalho se desenvolve, assim, com base em métodos e técnicas de investigação qualitativa, de acordo com a tradição da disciplina antropológica, que inclui instâncias de observação participante no âmbito dos espaços mencionados e realização de entrevistas - minuciosas - com distintos atores envolvidos.

O trabalho de campo incluiu, além disso, a consulta a leis e regulamentos antigos e em vigência. $\mathrm{O}$ interesse por essas fontes obedece a dois motivos fundamentais. Em primeiro lugar, a regulamenta- ção atual permite compreender o enquadramento legal dentro do qual se deve entender a organização da corporação policial. Não porque se acredite que esse enquadramento proporciona uma explicação a suas práticas efetivas, mas sim porque se entende que ele dá conta dos parâmetros que regulam sua mobilidade - ascensões, translados, advertências por meio da estrutura institucional. Em segundo lugar, as regulamentações antigas apresentam uma especial riqueza: explicitam, com caráter normativo, práticas que atualmente se tornaram óbvias. Seja qual for o caso, a interrogação de tais corpus permite vislumbrar, segundo a lei, um universo de sentidos. Isto é, uma certa caracterização de sua realidade simbólica e social.

Falar da instituição policial na Argentina, no singular, é uma óbvia generalização que não ignora as diferenças que podem caracterizar as agências policiais nacional e estaduais, mas aposta na ênfase das semelhanças de um sistema. Vale esboçar, no entanto, algumas das particularidades das delegacias consideradas no trabalho de campo, visando à compreensão dos lineamentos dentro dos quais se desenvolve o presente artigo.

Essa pesquisa foi realizada no contexto de forças policiais com jurisdição no âmbito da nação e da cidade autônoma de Buenos Aires por um lado e, por outro, no âmbito da província de Buenos Aires. ${ }^{2}$ A Lei de Organização de ambas as forças policiais indica que se trata de instituiçôes civis armadas, hierarquizadas e com caráter profissional, que cumprem funções judiciais e de segurança nos territórios designados. Para esclarecimento, cabe apontar que o trabalho de campo se desenvolveu em relação ao Agrupamento Comando, isto é, em relação à corporação policial voltada para funções de segurança, prevenção, repressão e manutenção da ordem pública.

A corporação policial se dividiu, tradicionalmente, em dois quadros: oficiais ${ }^{3}$ e suboficiais, ${ }^{4}$ com o primeiro tendo prerrogativa sobre o segundo e estabelecendo uma brecha não salvável entre o pessoal superior e o pessoal subalterno. ${ }^{5}$ A nova Lei da Corporação das Polícias da Província de Buenos Aires (Lei 13.201), sancionada no ano de 2005, estipulou, entre outras coisas, a criação de um único escalão policial para a PPBA, que suprime nessa 
força a antiga divisão entre oficiais e suboficiais e concentra em apenas nove posiçōes as anteriores hierarquias policiais. A irrupção de tal lei na cena policial bonaerense (da província de Buenos Aires) deixa sem efeito os lineamentos organizativos anteriores, compelindo-nos a uma reflexão mais profunda em torno do alcance e do poder dessas mudanças conforme a lei.

Em tempos de reformas, de mudanças mais ou menos abruptas ou mais ou menos sopesadas, qualquer modificação organizativa pode acarretar, ao menos em curto prazo, muito mais uma confusão estrutural do que sua conversão. No resguardo das resoluções, dos regulamentos e de suas modificaçōes, são as práticas - aprendidas, herdadas, tradicionais - que guiam o acionar dos sujeitos e dão conta de uma realidade institucional que, a despeito do que dita o formal, segue moldando o sentir e o entender de seus membros. Este trabalho é um estudo sobre os processos e sentidos em que essa compreensão institucional se constitui.

\section{II}

Episódio um. Aspirante a agente, Escola Federal de Suboficiais e Agentes, 1999. Fragmento de uma entrevista:

Penso que é na uniformidade da corporação que se capta toda a instrução que ela tem. Caso contrário, de nada adiantaria. Porque se o pessoal se apresenta malvestido, é porque os superiores não condicionaram o pessoal para que fosse uniforme. Se tenho uma pessoa com os sapatos mal lustrados, obviamente não há ninguém que a controle. É aí, desde o início, que começa a aparecer uma falha dentro da instituição. Então, acredito que o controle tenha de ser realizado. E de ser exigido. Dessa forma, vai se aprendendo como deve ser. Porque, caso contrário, depois, na rua, não somos bem vistos; a pessoa que está malvestida não é bem vista. A aparência causa impacto. Quando uma pessoa está bem vestida, passa totalmente despercebida. Mas quando está malvestida: "Nossa, olhem este policial como está, que horror!”. Causa impacto por demonstrar desleixo.
Episódio dois. Primeiro-sargento, PPBA, ferido em cumprimento do dever (fratura e encurtamento de uma perna). Declaração com motivo do ocorrido em uma cerimônia de reconhecimento oferecida pelo jornal La Palabra:

Havia levado os meninos. Fui fardado, com as medalhas. Significava uma honra muito grande. Mas, quando o delegado que estava naquele momento chegou, ele me disse: "O senhor não pode vestir a farda”, porque estava de licença médica. Tive de pôr um casaco para receber o prato; isso foi terrível para mim (Buenos Aires, 2002, p. 114).

Episódio três. Notícia jornalística:

Uma suboficial de polícia da cidade de Santa Fé tirou fotos seminua e em poses eróticas, ressaltadas com acessórios da farda, que também tem camisa e com a qual cobriu uma parte do corpo. As imagens chegaram a seus chefes. Agora ela está enfrentando um sumário administrativo e uma possível sanção.

A sensual morena de 20 anos aparece nas fotos com uma tanga preta e algumas partes da farda: uma camisa azul, um cinto com o porta-munição e o porta-algemas, e também realiza movimentos de ataque com o cassetete. Em outras duas, mostra suas nádegas, enfeitadas da mesma forma.

[...]

O sumário se abriu para esclarecer o fato e saber se a jovem que cometeu essa falta merece uma sanção leve ou uma drástica medida.

O debate está aberto, uma vez que na teoria seria uma falta leve, sancionada pelo artigo 41 da Lei 12.521 (nova lei policial), mas também é uma falta relativa ao decoro ou à altivez policial, que se agrava por aplicação do artigo 42 , em virtude da transcendência pública que teve o fato.

[...]

"Um funcionário deve observar em todo lugar e em qualquer circunstância a correção que a altivez policial exige", disse um jurista de Santa 
Fé. E uma fonte policial disse que "não se pode esquecer que se é um policial, mesmo estando de folga do serviço" (La Capital, 2007).

A farda é, ao menos à primeira vista, a marca distintiva de um policial. Aquela que o aponta como tal. Imagem da força policial, seu uso desencadeia múltiplos significados. Nele se expressa essa dinâmica de adscrição contrastiva que a força policial mantém em relação à sociedade civil (Sirimarco, 2009). Foi dito, nesse sentido, que a farda é uma ferramenta que permite separar a própria pessoa do mundo circundante: um tipo de construção defensiva contra uma realidade que se percebe em termos de caos (Bélohradský, 1981). A farda se ergue como uma barreira rigorosa. Nela, a pessoa e o mundo se encontram para se distinguirem. Farda e instituição são - ou pretende-se que sejam - uma coisa só.

Os três episódios anteriores giram em torno da farda, ou melhor, giram em torno de seu uso: dos significados que carrega, das imagens que habilita. Falam daquilo que evocam: a pulcritude, a honra, o desleixo, a vergonha. Seu uso - talvez por essa forte ligação que pretende não diferenciar instituição, pessoa e vestimenta - demarca fronteiras morais entre o permitido, o apto, o meritório e o ilegítimo. Essas marcas morais passam da farda para a pessoa, e vice-versa. Como uma segunda pele, ou melhor, uma extensão da própria pele, a vestimenta cobre e descobre, ao mesmo tempo, o corpo; dá indícios daquilo que se é. Como a farda vai unida ao indivíduo, indivíduo e farda constituem um todo.

A farda, enquanto superfície do corpo, transforma-se em uma pele social de signos e significados que representam o indivíduo institucionalmente socializado (Turner, 1995). A pretensão da instituiçãoo policial é imprimir o relato institucional nos corpos individuais. ${ }^{6}$ Não se trata somente da adoção de uma vestimenta, mas da aprendizagem de uma nova singularidade corporal, enquanto o traje imprime no corpo novos padróes de uso. Padrões de uso que não são apenas "anatômicos", mas também morais, como os episódios anteriores demonstram.

A farda compele o policial a uma nova aprendizagem: como mover-se usando botas, camisa, quepe e acessórios. E, ainda mais, o compele a mover-se, no contexto da instituição e da sociedade, conforme o trajar dessa farda. Para ambas as óticas, policial e civil, a farda se transforma em um tipo de investidura: é seu simples uso o que habilita ou desautoriza práticas e comportamentos, de tal modo que, nesse jogo entre pessoa e farda, já não é tão fácil distinguir quem deve ser merecedor de quem.

Este artigo se propõe a mergulhar nos discursos e sensibilidades que os três episódios mencionados habilitam, com o objetivo de colocar essas imagens dessemelhantes em relação dialógica. Isso tem a finalidade de ver o quanto se assemelham, o quanto se opõem e o quanto esses episódios se superpõem para avançar nos discursos institucionais e nas sensibilidades pessoais que os sustentam. E para adentrar, em suma, nesse universo polissêmico complexo que o território policial e seus relatos constituem.

Se a instituição policial faz de sua farda uma imagem de si mesma, e se propóe esse relato para pensar-se, a proposta deste trabalho, então, é desentranhá-lo. Isto é, desarmá-lo em seu sentido último: tomá-lo não como um espaço unívoco e clausurado de sentido, mas como um território em disputa, onde indivíduo e instituição - policiais e força policial - intercambiam imagens e significados; onde articulam, em um diálogo sempre constante e sempre em combate, o conteúdo real desse simbolismo e, por isso, desse relato; onde colocam em ação, por meio de modalidades efetivas de uso, o alcance simbólico dessa farda. O relato acerca da farda, em virtude de suas possibilidades performativas, constrói-se, como vimos, a partir de seu próprio exercício de uso. A farda policial constitui um espaço em disputa que se tensiona em pleno ato.

Dessa forma, se esse relato funciona como uma figura de pensamento, capaz de orientar o discurso em uma direção específica, adentrar nos sentidos que giram numa espécie de rodamoinho e se sedimentam em torno da figura da farda policial torna-se uma maneira de começar a tematizar, a partir dos fluxos de sentido que fervilham sob ela, os modos concretos como instituição e indivíduos têm de pensar-se.

\section{III}

A farda pode ser uma arena repleta de prescriçôes e de contrastes que insere aquele que a porta 
na estrutura institucional. ${ }^{7}$ Mas, de acordo com os objetivos deste trabalho, o importante é concentrar-se nos traços que a posicionam como um todo institucional. Isto é, que posicionam o traje policial, considerando a sociedade civil justamente como uniformizada, não só em sua estética, mas em seu sentido. A farda é a perfeita sinédoque da instituição: a parte que fala pelo todo. Quais são, então, as diversas expressões com as quais a farda "fala" pela instituição policial?

A consideração da farda enquanto transmissor de sentidos implica, em primeiro lugar, concebê-la como ferramenta de trabalho. Isto é, como uma instância a mais, a partir da qual se desempenha o ofício policial. A esse respeito, o Manual práctico para el personal subalterno instrui a corporação a vestir a farda sempre de forma impecável, a fim de que baste a sua presença para provocar uma corrente de simpatia, impressionando favoravelmente em seu acionar e reduzindo, dessa forma, a apreensão que algumas pessoas sentem diante da presença policial (1997, pp. 22-23).

Proposta dessa forma, a farda, ou melhor, seu asseio e correção transformam-se em um dispositivo útil para alcançar a simpatia da sociedade civil e impressioná-la favoravelmente. A boa imagem da instituição é alcançada a partir da boa imagem de seus membros, e a boa imagem deles deriva da boa imagem de seus trajes. Ocorre, assim, uma "corrente de simpatia" que descansa, ao menos em primeira medida, não em práticas, mas em aparências, em que a simetria entre o corpo físico e o corpo institucional se repete na correlação entre esses corpos físicos e o corpo moral:

Um policial que se apresenta com sua vestimenta suja ou rasgada, ou com qualquer uma das peças em desalinho, não pode captar a simpatia e a estima que merece.

Já o policial que veste uma roupa em bom estado, bem passada, sem manchas que a desmereçam, que, em uma palavra, veste-se pulcramente, desperta simpatia e é bem visto por todas as pessoas que o rodeiam, que o requerem ou simplesmente o observam.

O esmero da pessoa, tanto nos detalhes do físico como no que tange a sua farda e com- plementos, deve ser estritamente observado e cumprido (Argentina, 1979, pp. 34-35).

As palavras do aspirante no primeiro episódio não poderiam ser mais certas. Assim, de índices físicos derivam propriedades morais: a farda amarrotada torna-se causa de desconsideração e o cabelo em desalinho é sinal evidente de antipatia. A essa concepção se alia o paralelismo, tão estimado pelo positivismo, entre corpo físico e corpo moral, em que o primeiro resulta em um exato correlato do segundo e ambas as condiçóes se confundem em uma só. A farda não só vem a ser uma representação da moralidade institucional como também uma modalidade para sua própria construção. Acredita-se que na ausência de amarrotamento e de manchas repousa a "correção moral" que se desprende da física, em que a pulcritude no vestir é tanto a prova como a causa dessa moralidade.

Enquanto signo polissêmico, a farda pode ser utilizada para ativar também outros significados:

$\mathrm{Na}$ realidade, a farda já assusta um pouco, dá um pouquinho de autoridade. Não digo que as pessoas vão se assustar com uma farda, mas dá um pouquinho de... Se você está tomando uma cerveja com um amigo e de repente passa um policial, você diz: "Ih, puta que pariu". Agora já não é assim, está se perdendo um pouco isso. Mas se a polícia te olha e diz: "Joga essa cerveja fora e suma daqui”, o mais provável é que você jogue a cerveja fora e vá embora. E vai dizer: "Não quero problemas com eles, não". ${ }^{8}$

Fica claro que a farda pode atuar também como ferramenta para a imposição de um dos pilares sobre os quais descansa o exercício do poder policial: a autoridade. Só a sua presença já é signo dessa intimidação, desse "susto", que não é a farda per se, mas sim a instituição que a sustenta e a promove como uma eventual metodologia de trabalho. A farda se torna, então, um mecanismo para a dissuasão e a diminuição, um instrumento para a coação, que faz do temor o método no qual se baseia o bom desempenho da função policial (Sirimarco, 2004). Seu "trajar", em suma, habilita um exercício de autoridade que não reside no respeito, e sim na intimidação. 
É que o respeito é outro dos eixos em torno do qual se constrói a simbologia da farda. Certa vez, um comissário maior relembrava os (bons) velhos tempos em que o guarda da esquina era um amigo dos vizinhos, a todos conhecia e era por todos respeitado. E sintetizava essa nostalgia na seguinte fórmula: "se respeitava a farda, porque estava lustrada, limpa. Hoje cospem nela, até a xingam, olham para ela com deboche. Já não existe respeito".

A farda, mais do que uma vestimenta de trabalho, é uma investidura. Vesti-la é ter sido transformado por sua eficácia simbólica, que não só projeta uma determinada imagem sobre os outros mas também transforma a imagem que a pessoa tem de si mesma, ao mesmo tempo em que modifica a partir dessa farda - as atitudes dos outros e as próprias, numa tentativa de ambas para ajustar-se a essa nova imagem (Bourdieu, 1993). Porque não se trata somente de um indivíduo apropriando-se de uma função - a policial, nesse caso -, mas também do movimento inverso, já que o sujeito "só toma posse de sua função se aceita deixar-se possuir por ela em seu corpo" (Bourdieu, 1999, p. 22). Nesse sentido, o comportamento que se deve a esse uniforme policial é o respeito que se deve à instituição.

\section{IV}

Indicador de moralidade e de respeito, a farda é, sobretudo, um índice de honra, sinal do orgulho de pertencer à instituição: "É uma honra vestir a farda da Polícia Federal. A propriedade de seu uso deve ser sempre correta e exigida conjuntamente com a postura" (Argentina, 1947, art. 1).

Se para o indivíduo deve ser uma honra vestir a farda policial, seu uso correto é, como demonstra essa normativa, imprescindível para a honra da instituição. A farda torna-se assim, uma vez mais, símbolo bivalente, que expressa tanto a honra individual - o orgulho da adscrição - como a honra institucional. Porque a honra é um atributo coletivo, que se alimenta das honras individuais dos membros dessa totalidade (Pitt-Rivers, 1979). Tal como sucede com a honra de uma família, que se deriva da conduta de seus diferentes membros, também, na sempre proclamada "família policial", a honra institucional resulta da somatória das honras individuais. No uso da farda, em sua correção e em sua postura, se dirime parte dessa honra institucional. A seguinte normativa bem pode ser entendida no contexto dessa argumentação: "Aos oficiais, quando estiverem fardados, fica proibido carregar pacotes ou envoltórios que, por suas dimensões ou confecção, não tiverem relação com o decoro do mesmo" (Argentina, 1947, art. 12).

Argumentou-se que o caráter da farda policial como indicador de status se assenta em sua monopolização. Isto é, em sua capacidade para reunir e esgotar qualquer sinal de status ou hierarquia: enquanto a pessoa está de uniforme, o que está suprimido é qualquer outro indicador de status. Sobretudo, de status civil. Ao portador de uma farda não se permite ter, sobre seu próprio corpo (sobre sua própria farda), qualquer marca que $\mathrm{o}$ assemelhe ao cidadão comum, a suas práticas e atitudes. $\mathrm{O}$ que parece ser proibido para os que usam farda é a confusão com a imagem última da domesticidade (Joseph e Alex, 1972).

Se a farda é a pele coletiva institucional que se imprime sobre as peles individuais, qualquer impureza que a toque é, diretamente, uma mancha sobre a imagem da força. A farda, enquanto investidura que consagra o sujeito dentro do papel de policial, não pode ser desonrada com pacotes que "sujem" sua prestância. Ou melhor, não pode ser desonrada com objetos que, por sua natureza, resultem inconvenientes para a função policial. A inconveniência dos objetos pode ser transladada a algum lugar: a farda tampouco pode ser usada: "[...] para participar como espectador de eventos esportivos ou reuniōes desse tipo, ou para ir a lugares com atividades alheias à atividade institucional em atenção a suas características e objetivos" (Argentina, 1997, p. 48).

A honra da farda parece desprender-se de seu contexto, seja este um objeto que se une à farda ou um lugar ao qual se comparece fardado. Seguindo essa lógica, não é de se estranhar que a farda tampouco possa se distinguir em relação a outra trama passível de ser objetada: a própria pessoa: "O membro da corporação enfermo ou convalescente ou que, por qualquer outra circunstância, não puder usar a farda com a marcialidade e a correção correspondente deverá estar à paisana; para esses casos é 
necessária a autorização correspondente" (Argentina, 1997, art. 11).

Vale lembrar, as palavras do primeiro-sargento reunidas no episódio dois. A ponto de receber uma condecoração, preparou-se com uniforme e medalhas. Isto é, tinha se engalanado, no sentido de compor-se com as melhores galas. E recebeu uma ordem que não esperava: a de ocultar seu uniforme com um casaco. Isto é, a de invisibilizar, por estar em "licença médica" (em virtude da condição de enfermo), seu pertencimento à instituição.

A "licença médica", no exemplo desse primeiro-sargento, é somente um eufemismo, como bem explicita o regulamento anteriormente visto; o irreconciliável com o traje policial não é tanto a enfermidade em si, mas a falta de postura que dela possa desprender-se. Tendo em conta que o primeiro-sargento transitou por sua situação médica de cadeira de rodas, muletas e bengalas, uma pessoa poderia supor, analisando nos mínimos detalhes, que o irreconciliável com a farda policial é, simplesmente, o corpo imperfeito: o corpo que, por causa de uma lesão, obstrui a possibilidade de um corpo físico em concordância com os mandatos institucionais, e que obstrui também a possibilidade de um registro idealizado de atuação policial.

Caberia então pensar, nesse caso, que a construção institucional do corpo, tanto quanto a da corporalidade - um policial saudável, forte, aguerrido -, torna-se instância árdua de sobreimprimir nos sujeitos lesionados (Sirimarco, 2009a e b). Ou, dito com as palavras de um oficial inspetor que está em uma cadeira de rodas por causa de um enfrentamento e ao qual foi negado um trabalho como professor: "um Policial inválido não era uma boa imagem para os aspirantes" (Buenos Aires, 2002, p. 172). Nesse jogo, em que a farda é a instituição, é de mister que esta permaneça impoluta. Para isso, a farda deve permanecer imaculada; o próprio corpo pode se tornar uma mancha.

O exemplo narrado no episódio três parece confirmar, peremptoriamente, essa afirmação. Todos recordarão as fotos, seminua e em poses eróticas, de uma suboficial de Santa Fé que lhe valeram um sumário administrativo, justamente por aparecer nelas com elementos da farda policial (camisa, algemas, cassetete). O rebuliço desencadeado com o surgi- mento dessas fotos estava menos relacionado com o erotismo das fotos em si do que com a inclusão de elementos policiais: camisa azul, algemas e cassetete sobre um corpo seminu que tinham sido convertidos em inequívocos reforçadores da cena erótica.

Uma longa lista de exemplos poderia ter sido trazida à baila para ilustrar o fetichismo construído em torno de uniformes e seus acessórios. Sem nos determos excessivamente nesse tópico, vale a pena ressaltar, entretanto, o discurso de virilidade e poder que parece subjazer nesses casos, entrelaçado com fantasias de dominação e controle. A arma - porque o cassetete e as algemas não são outra coisa - ocupa, nesse contexto, um espaço singular. Nesse mapa narrativo que é o corpo, qualquer tipo de arma se torna, a meu ver, um lugar corporal de significação especial, um elemento privilegiado na gramática com a qual o corpo policial fala. A arma o designa e o narra. Como a camisa distintivamente azul, uma "marca visível" que escreve sobre esse corpo um determinado discurso de domínio. Transforma-se assim em uma instância central na narrativização do sujeito policial como sujeito de poder.

O caso da suboficial de Santa Fé excede, entretanto, esse paradigma interpretativo. Para o olhar institucional, uma coisa é que uma pessoa pose eroticamente de uniforme policial, outra coisa bem diferente é que essa pessoa, além disso, seja policial. $\mathrm{O}$ que, no primeiro caso, cai sob a égide do mero fetichismo torna-se, no segundo, uma falta de respeito em seu sentido mais literal. A camisa e o cassetete não são simples acessórios: são elementos concretos de seu uniforme de trabalho. A injúria procede, como já se viu, em decorrência de a farda estar no contexto inadequado.

Inteirado do fato, o ex-chefe da Polícia de Santa Fé respondeu às acusações sustentando que "o ato da suboficial é terrível, uma falta de ética na carreira policial", pois "a farda, para o policial, é algo sublime, é a segunda pele", e inclusive "é utilizada como mortalha" por muitos agentes (Rosario $3,2007)$. O erro da suboficial, ao que parece, foi ter se equivocado no contexto de atuação do "sublime". Foi ter atacado, com um simples gesto, a respeitabilidade de toda a instituição policial, ao ter denegrido - nas palavras de Joseph e Alex (1972) o emblema totêmico do grupo: a farda. 
A farda se mancha quando é exibida sobre corpos imperfeitos, em lugares inconvenientes ou em poses inadequadas. Essas situações descritas podem ter muito de rompimento, mas, finalmente, o que foi delimitado como não apto não faz outra coisa senão enfatizar o que se entende como viável. Assim, a incapacidade de certas pessoas para trajar o uniforme policial reforça, a partir da rejeição que gera, o desempenho da corporalidade institucionalmente esperada - pulcra, alinhada, correta, decorosa.

Se essas pessoas incapazes de portar a farda falam das que realmente são capazes é porque os que falham em desenvolver-se segundo o modelo proposto pela instituição demonstram, com seu constrangimento, o que não se pôde alcançar. Deter-se nesses impedimentos do uso da farda constitui, então, uma maneira de regressar aos usos do corpo e da vestimenta que a agência policial constrói como desejáveis. Nada como a mácula - de lugares, de objetos, de pessoas - para prestar atenção novamente ao que deve ser respeitado. Esse contexto de significação, em que a pessoa pode se tornar uma mancha, é o resultado óbvio de um movimento anterior: o de considerar a farda per se sacrossanta.

\section{V}

Em setembro de 2004, realizou-se, nas dependências da Escola Superior de Polícia da PPBA, um curso de "Mística Policial". Os palestrantes, dois coronéis reformados do Exército, discorreram acerca da necessidade de "recriar a mistica da Polícia da Provincia de Buenos Aires". Monologavam, entre outras coisas, sobre:

[...] o mito do anjo da guarda que é a polícia. Nós somos na Terra os responsáveis, que fazem com que essa figura do anjo da guarda se encarne em mim, em minha simples farda. Eu materializo essa proteção. Nós nos esquecemos de que temos uma farda, que temos uma missão [...] Porque nenhum de vocês tem vergonha de usar a farda!

Os rostos que, durante a palestra, eram fiéis imagens da concentração e da atenção abandona- vam a máscara nos minutos de descanso e revelavam seu fastio. Enquanto os coronéis foram tomar café, muitos no auditório deixavam ouvir - em voz baixa, é claro - suas apreciações. "Quanta abobrinha junta, cara?", sintetizava nada diplomaticamente um dos oficiais participantes. Diante desse auditório, a arenga final - "nenhum de vocês tem vergonha de usar a farda" - resultava fora de lugar.

A farda, para o policial, é algo sublime, defendia no parágrafo anterior o ex-chefe da Polícia de Santa Fé. Nele se encarna a figura do anjo da guarda que é a policia, argumentam os palestrantes em algumas linhas acima. Seu parecer traduz o discurso oficial: aquele que amalgama farda e instituição faz descansar sobre a primeira o respeito que deve ter para com a segunda.

Os comentários dos participantes da palestra narrada sugerem uma pergunta: o que sucede quando a sensibilidade individual ${ }^{9}$ não coincide com o sentir institucional? Isto é, quando a farda condensa, para os policiais, atributos contrários aos apontados pela força policial.

A história da dissidência tem longa data. No final do século XIX, quando a tradiçãao policial começava a construir-se e o sentimento de "comunidade e honra policial" era algo, todavia, inexistente, era costume do grupamento (Romay, 1966, p. 139):

[...] efetuar alteraçóes na farda. Em 10 de abril de 1875 , foi proibido severamente que os vigilantes as fizessem, "ter a farda desabotoada, usar lenços no pescoço, botas por fora da calça e ginetas ou números adornados com fitas de cores diferentes e, finalmente, apresentar-se com o maior asseio possível e no caso de os vigilantes serem vistos infringindo essa disposição seriam arrestados".

O cronista acrescenta um dado revelador ao pé da página: a alteração das calças regulamentares consistia em incorporar mais tecido "a fim de parecerem bombachas" (Romay, 1966, p. 139). Lenço no pescoço, botas por fora da calça, calças que parecessem bombachas. $\mathrm{O}$ que se pretendia era uma aparência - determinada pela época - de "civilidade". Aquilo que sob a perspectiva institucional era concebido como um meio de reconhecimento da 
autoridade e um elemento de dignificação do vigilante era vivenciado, a partir da posição de quem o portava, com sentidos contrapostos. Para esses vigilantes, que ingressavam na polícia quando não havia outra opção, que intercambiavam as funçōes policiais com as de peão ou de jornaleiro (Gayol, 1996), a alteração da farda representava uma modalidade de aproximação à indumentária civil e uma tentativa, por conseguinte, de não se diferenciar da sociedade.

Práticas similares podem ser encontradas na atualidade. Evidentemente, o tempo e a realidade institucional são outros. Os sentires, mesmo em circunstâncias incomparáveis, não deixam de ser afins: revelam uma valorização do uso da farda muito distante da vontade institucional. Vem à luz a tensão que pode existir em ocasiōes entre o discurso institucional sobre a farda e a vivência de seu uso. Se o longínquo vigilante do século XIX tentava camuflar sua farda regulamentar com fitas coloridas ou lenços, o atual oficial escolhe chegar a seu lugar de trabalho com a farda em uma bolsa. Ambos demonstram, com sua atitude, que orgulho e honra não são atributos privativos do traje policial - tampouco de pertencimento à instituição.

Para muitos policiais, vestir a farda torna-se não um orgulho a proclamar, mas um estigma a ocultar. "No seu bairro, você não pode ser policial", comentou um oficial da PPBA. E relatava como saía de sua casa sem usar a farda. "Os vizinhos não sabem que sou policial, por uma questão de não me delatar", acrescentou. Atitudes semelhantes e subterfúgios se repetiram em quase a totalidade dos oficiais que estavam fazendo o curso nesse estabelecimento. "Eu ando sem pistola, tento andar o menos possivel fardado. Não me sinto apoiado nem pelas pessoas nem pela instituição, por ser policial 24 horas, por sair para ser morto", concluiu outro oficial.

Esse tipo de "ocultamento" não se relaciona (somente) com estratégias de proteção, e sim com a vivência do desprestígio e da rejeição - e até do perigo - que o pertencimento institucional desperta: "Você não sabe o que é voltar [de La Plata] a meu bairro em Buenos Aires fardado. Uma vez, uma vizinha, quando me viu, segurou com força a mão da menina que estava com ela. 'A menina se assustou', a senhora me disse".
Essas vozes põem em tensão o discurso institucional, que ativa em torno da farda símbolos de correção moral, de respeito ou de orgulho. E vêm à tona as fissuras que essa pretensão esconde, de uma "comunidade policial" ancorada no orgulho do pertencimento, revelando que, se a farda pode ser, para alguns, um "corpo sacrossanto" que tem de ser protegido da desonra, para outros ela mesma pode se tornar uma mancha. Aquilo que representa o estigma fica então em disputa: torna-se um sinal vazio que pode estar repleto de um e de outros argumentos. Finalmente, é de onde parte o olhar de que a farda pode se converter tanto em uma metáfora da virtude quanto do escárnio.

Os preocupados com a "santidade" da farda pretendem que ela seja um ponto de convergência do olhar social: eles a constroem como o espaço ao qual tais olhares confluem. Conforme essa construção - enquanto território institucional sempre visível -, a farda deve ser erigida como um sinal que, ao atrair o olhar social, se encerra em uma única gama de significados: o orgulho, o respeito, a honra. A instituição policial compele os seus membros e os de fora a dirigir o olhar para algo (sua vestimenta). Ao fazer isso, não só direciona esse olhar - apontando o objeto a ressaltar - mas também dirige sua modalidade. A instituição nos diz o que olhar e o que ler no que vemos.

Os episódios antes narrados são muito eloquentes quanto a isso: uma farda asseada sobre um corpo saudável, limpo e decente é sinal inequívoco de respeitabilidade e de correção moral. Assim deve ser vista e valorizada a vestimenta policial e, portanto, a instituição como um todo. A farda se torna, assim, um locus de poder e de visibilidade, um elemento que atrai a atenção. Melhor ainda: um elemento que deve ser visto em seu esplendor, para ressaltar a presença da autoridade e conferir-lhe sua relevância.

O problema surge quando o olhar tem uma interpretação tergiversada. Quando aumenta o risco de se ler, nessa farda, uma valorização distinta da institucionalmente pretendida. Quando o corpo de um policial de cadeira de rodas introduz, nesse texto pretensamente limpo que é a farda, um elemento discordante que pode trazer perigo à narração institucional. Isto é, quando a vestimenta se converte em algo que, ao ser visto, acarretaria uma leitura 
inconveniente. $\mathrm{O}$ objeto que era antes monopolizador do olhar deve, de qualquer maneira, separar-se dele. A farda deve ser ocultada com um casaco, deve desaparecer da cena narrativa. Não pode, em uma palavra, transformar-se em um suporte de significados que faça oscilar o relato institucional da prestância, da autoridade e do poder.

O episódio da policial de Santa Fé ilustra até que ponto o que deve ser visível (a farda) pode, de um momento para outro, tornar-se obsceno. Pois obsceno é, em seu sentido mais literal, o fato de colocar em cena o que deveria ter permanecido fora da vista (ob-scana), o fato de conferir visibilidade ao que deveria ser imperceptível (Sirimarco, 2009a). A farda mencionada torna-se, nesse uso e nesse contexto, simplesmente inaceitável: desloca, em virtude do olhar que propõe, qualquer significado admissível para a instituição policial. O contexto se transfere para a farda, transmitindo-lhe, em último lugar, os valores que se desdobram no primeiro. A falta de ética que o ex-chefe da força imputa à policial de Santa Fé reside justamente na inclusão do traje policial em semelhante cena: em tê-lo exposto à vista de todos, em tê-lo magnificado ante esse olhar do outro e em ter ressaltado, em suma, o que deveria ter ficado, em virtude do contexto, fora do campo de visão.

No entanto, é interessante constatar que, no caso dessa policial, se a farda aparece na cena é justamente para a efetividade de uma narração em torno de significados que não necessariamente discrepam dos admitidos institucionalmente. Como mencionei anteriormente, a camisa, as algemas e o cassetete não fazem outra coisa senão reforçar a narração das fotos em torno de um eixo sensual: é no sentido da farda como índice de autoridade, domínio e poder que reside a eroticidade da cena. Assim, a farda se explica pelos significados que institucionalmente reveste, embora dê margem a uma leitura que a força policial pode não considerar legítima. Poderia ser dito, nesse caso, que a farda é utilizada para construir um relato diferente com base nas grafias compartilhadas.

O que falha, claramente, é o contexto (entorno, pessoa ou corporalidade). É em virtude dessa gestualidade indecorosa que os significados genuínos da farda se tornam ilegítimos. A pessoa, uma vez mais, escurece-a com sua mácula. Nesse contexto, pouco importa que a farda se mantenha coerente com o sentido institucional. Parece, então, que o sancionável resulta da acentuação exagerada de certas peculiaridades (autoridade, poder, domínio) fora de seu contexto legítimo de atuação. Ou melhor, da descontextualização dessas peculiaridades, de seu isolamento do contexto pertinente que o impregne de sua "santidade". Individualizados, recortados de seu contexto, esses sentidos que a farda traz consigo são indigeríveis. É sua re-encenação o que resulta obsceno.

Se assim ocorre, é porque a figura perde a aura de "santidade" e fica em evidência como deboche. O suporte perde seu sentido, por ser visto contextualmente recarregado, e se torna paródico. A policial de Santa Fé atua corretamente quanto à semiótica de seu uniforme, de tal modo que a correção se torna, por excesso, questionamento. $\mathrm{O}$ excesso deriva, é claro, da contraposição do correto e do inconveniente: o sentido último da farda ressalta-se demasiadamente no meio de um entorno incorreto. Assim ostentada, a farda dessa policial não faz mais do que pôr em dúvida esses significados legítimos. A atuação exagerada da norma (autoridade, domínio, poder) a põe em evidência: a pose erótica inverte ironicamente a autoridade que deve emanar dessa vestimenta e instaura essa distância crítica sem sequer se afastar dos significados que a força policial confere à farda (Sirimarco, 2009a).

Esta se torna, assim, um suporte capaz de ser impregnado de múltiplos significados: do sacro ao estigma. Já em 1912, Durkheim (1968, p. 420) nos advertia de que o sagrado abrange tanto o santo quanto o maldito.

O impuro e o puro não são dois gêneros separados, mas duas variedades de um mesmo gênero, que compreende todas as coisas sagradas. Há dois tipos de sagrado: um fausto e outro nefasto, e não há solução de continuidade entre as duas formas opostas, mas um mesmo objeto pode passar de uma à outra sem mudar de natureza. Com o puro se faz o impuro, e reciprocamente. A ambiguidade do sagrado consiste na possibilidade de tais transmutaçōes.

Os exemplos analisados parecem reforçar esta hipótese: a ambiguidade do sagrado radica-se na 
simples modificação das circunstâncias exteriores em uma circunstância que pode colorir diferentemente um mesmo processo fundamental.

Assim, de um determinado entorno, de um determinado corpo, depende a qualidade do sagrado. Nos episódios analisados neste trabalho, são os corpos que narram uma história que pode ser tanto legítima quanto inconveniente ou obscena. $\mathrm{O}$ aspirante, o policial de cadeira de rodas ou a policial de Santa Fé, todos interferiram com os significados que a instituição policial atribui a sua farda, para legitimá-los, para replicá-los ou para dar-lhes um caráter pessoal. Em última instância, se fixar o tom do sagrado pode ser monopólio do acionar institucional, reverter o fausto em estigma (ou vice-versa) é também responsabilidade e mérito das sensibilidades individuais.

É neste ponto que se abre uma interessante linha de reflexão, que permite voltar ao início deste trabalho. Como policiais e instituição policial disputam os sentidos em torno da figura da farda ou do uniforme policial? Que tensōes se desnudam em torno da farda enquanto relato? Que pluralidade de vozes e de estratégias permite construir, finalmente, um relato institucional? Se nenhuma instituição é uma entidade com existência própria, mas certamente um modo de relação entre indivíduos, é óbvio que seus relatos não podem ser monocórdios.

Os episódios revisados desnudam a tensão que se mascara sob a construção institucional da farda como relato acabado ao expor a distância que media entre os valores que a instituição e os policiais finalmente lhe atribuem. Tais episódios põem a descoberto, de maneira inquestionável, que mais além de um sentido último e acordado, o que tal figura esconde é um território de asperezas. O policial com a licença médica e a policial de Santa Fé enfrentam o imperativo da farda com o ensaio de um uso do traje puramente pessoal. Seguindo os elos institucionais que ligam farda e instituição, se poderia pensar que o que propōem é, finalmente, outro registro a partir do qual se deve assimilar e compreender o policial.

A pergunta, que está perfeitamente ancorada no relato até agora trabalhado, ou o supera, pode ser resumida do seguinte modo: como se constrói e se reapropria o relato institucional? Bruner destaca (1991) que as narrativas não existem em um mundo real, onde esperam pacientemente ser refletidas, de maneira verídica, em um texto. Construir uma narrativa não implica algo como selecionar uma série de eventos de um lugar - seja este a vida real, a memória ou a fantasia - para colocá-los em seguida na ordem apropriada. $\mathrm{O}$ ato de construir um relato é muito mais que isso: implica a construção dos próprios eventos à luz da narrativa total, de maneira que estes possam, a partir dessa constituição especial, tornar-se funçóes específicas da história a narrar. O objetivo deste trabalho reside em desentranhar a figura da farda ou do uniforme policial. Debruçar-se sobre o que o tema tem de relato institucional foi, ao mesmo tempo, um modo de analisar essa narrativa total que é a força policial.

\section{Notas}

1 Escuela Federal de Suboficiales y Agentes (Policía Federal Argentina - PFA), Escuela de Policía "Juan Vucetich" (Policía de la Provincia de Buenos Aires PPBA), Liceo Policial (PPBA), Escuela Superior de Policía (PPBA).

2 O estado mais extenso e povoado do país, que se limita com a cidade de Buenos Aires, capital da Argentina.

3 Oficial ajudante, oficial subinspetor, oficial inspetor e oficial principal (oficiais subalternos); subcomissário e comissário (oficiais chefes); comissário inspetor, comissário maior e comissário geral (oficiais superiores).

4 Agente, cabo, primeiro-cabo, sargento, que correspondem à hierarquia de suboficiais subalternos; primeiro-sargento, suboficial escrevente, suboficial auxiliar e suboficial maior, que correspondem à hierarquia de suboficiais superiores.

5 Salvo ascensão por meio de um reconhecimento post mortem.

6 Falar de corpo não implica fazer menção ao mero corpo físico, mas sim entendê-lo como um objeto material e uma fonte de subjetividade; um locus de consciência e sensações (Jackson, 1983; Crossley, 1995). Falar do corpo é falar do sujeito sob outra ótica.

7 Só para o olho pouco observador, o traje policial é uniforme. Para o olho treinado em distinguir as diferenças (com o objetivo de não incorrer na falha de desrespeitá-las), não é assim nunca. Nas modalidades diferenciais de seu uso se representam as relações hierárquicas.

8 Entrevista com um aspirante, 1999.

9 É lógico que a oposição entre discurso institucional e 
sensibilidade individual funciona apenas em termos analíticos. Pretende apontar, em relação ao uso da farda, a existência de sentires contrários àquele que a voz oficial ressalta.

\section{BIBLIOGRAFIA}

ARGENTINA. (1947), Reglamento de uniformes. Buenos Aires, Gráfica de la Policía Federal. (1979), Manual práctico para el personal subalterno. Buenos Aires, Editorial Policial. (1997), Manual de instrucción para el personal policial. Buenos Aires, Policía Bonaerense.

BÉLOHRADSKÝ, Václav. (1981), "Introduzione", in K. Jozef (org.), Il corpo e l'uniforme. Appunti per una civilità mitteleuropea, Forlì, La Nuova Agape.

BOURDIEU, Pierre. (1993), "Los ritos como acto de institución", in J. Pitt-Rivers e J. G. Peristiany (eds.), Honor y gracia, Madri, Alianza Editorial.

(1999), Meditaciones pascalianas. Tradução de Thomas Kauf. Barcelona, Editorial Anagrama.

BRUNER, Jerome. (1991), "The narrative construction of reality". Critical inquiry, 18 (1): 1-21.

(1998), "What is a narrative fact?". The annals of the American Academy of Political and Social Science, 560: 17-27.

BUENOS AIRES (PROVÍNCIA). (2002), Con honor y dolor. La Plata, Editorial Policial de la Provincia de Buenos Aires.

CROSSLEY, Nick. (1995), "Merleau-Ponty, the elusive body and carnal sociology". Body \& society, 1 (1): 43-63.

DURKHEIM, Émile. (1968), Las formas elementales de la vida religiosa. Tradução de Iris Josefina Ludmer. 1. ed. Buenos Aires, Editorial Schapire.

GAYOL, Sandra. (1996), "Entre lo deseable y lo posible. Perfil de la policía de Buenos Aires en la segunda mitad del siglo XIX". Estudios sociales, 10: 123-138.

GIDDENS, Anthony. (1984), The constitution of society. Outline of the theory of structuration. Berkeley/Los Angeles, University of California Press. JACKSON, Michael. (1983), "Knowledge of the body". Man, 18 (2): 327-345.

JOSEPH, Nathan \& ALEX, Nicholas. (1972), "The uniform: a sociological perspective". American Journal of Sociology, 77 (4): 719-730.

LA CAPITAL. (2007), "Investigan a una policía de Santa Fe por sus fotos eróticas con uniforme". Rosario, 5 de julho. Disponível em <http:// archivo.lacapital.com.ar/2007/07/05/general/ noticia_401309.shtml>.

LEWKOWICZ, Ignacio. (2004), Pensar sin estado. La subjetividad en la era de la fluidez. Buenos Aires, Paidós.

OCHS, Elinor \& CAPPS, Lisa. (1996), "Narrating the self". Annual review of anthropology, 25: $19-43$.

PITT-RIVERS, Julian. (1979), Antropología del honor o politica de los sexos. Ensayos de antropología mediterránea. Barcelona, Editorial Crítica.

ROMAY, Francisco. (1966), Historia de la policía federal argentina, tomo $V$. Biblioteca Policial, Buenos Aires.

ROSARIO 3. (2007), "No habría delito en las fotos eróticas de la suboficial santafesina". 5 de julho. Disponível em <www.rosario3.com/noticias/policiales/noticias.aspx?idNot=15091>.

SIRIMARCO, Mariana. (2004), "Acerca de lo que significa ser policía. El proceso de incorporación a la institución policial", in Sofía Tiscornia (comp.), Burocracias y violencia. Estudios de antropología politica, Buenos Aires, Antropofagia. (2009a), De civil a policía. Una etnografía del proceso de incorporación a la institución policial. Buenos Aires, Editorial Teseo.

(2009b), "Policías. De los cuerpos legitimos a los cuerpos reales", in R. Kant de Lima, Sofía Tiscornia e Lucía Eilbaum (orgs.), Burocracias penales, administración institucional de conflictos y ciudadanía. Experiencia comparada entre Brasil y Argentina, Buenos Aires, Antropofagia.

SPIVAK L'HOSTE, Ana. (2010), El Balseiro. Memoria y emotividad en una institución científica argentina. La Plata, Editorial Al Margen.

TURNER, Terence. (1995), "Social body and embodied subject: bodiliness, subjectivity and sociability among the Kayapo". Cultural anthropology, 10 (2): 143-170. 


\section{A VIDA COM FARDA: A VESTIMENTA POLICIAL COMO RELATO INSTITUCIONAL EM DISPUTA}

\section{Mariana Sirimarco}

Palavras-chave: Instituição policial; Farda; Relato institucional.

Toda instituição constrói relatos que a sustentam. Narrativas que encenam discursos, vivências e valorizações para, a partir daí, entender-se como grupo social e como instituição. Este trabalho pretende abordar um dos relatos institucionais mais caros à força policial: a farda como investidura. Se me proponho a abordar a figura da farda em tais termos é porque entendo que, em torno dos símbolos que ela encarna, constrói-se um entendimento tanto do indivíduo que o porta quanto do grupo a que ele pertence. É nesta veiculação de entendimentos que reside seu sentido de relato, capaz de funcionar como uma figura de pensamento e de orientar o discurso em uma direção específica. Adentrar-se nos sentidos, que giram numa espécie de rodamoinho e se sedimentam em torno da figura da farda, é uma maneira de começar a tematizar os modos concretos pelos quais instituição e indivíduos pensam a si mesmos.

\section{LIFE IN UNIFORM: POLICE UNIFORM AS INSTITUTIONAL STORIES IN DISPUTE}

\section{Mariana Sirimarco}

Keywords: Police institution; Police uniform; Institutional story.

Institutions build stories to support them; narrations that stimulate speeches, experiences and values from which to think themselves as a social group and an institution. This paper intends to analyze one of the fondest institutional stories of police agency: the uniform as an investiture. The author states the figure of the police uniform in such terms because the symbols embodied in it allow for building an understanding both of the individual wearing the uniform and of the group to which he belongs. Upon that professional and moral understanding lies the sense of the story, which is capable of functioning as a figure of thought and of guiding thespeech in a certain direction. Going deeper into the senses, thatswirl andsettle around the figure of the police uniform, is, finally, a way of beginning to analyze the concrete modes through which individuals and institution think about themselves.

\section{LA VIE EN UNIFORME: L'HABILLEMENT DE LA GENDARMERIE ET DE LA POLICE EN TANT QUE RÉCIT INSTITUTIONNEL EN DISPUTE}

\section{Mariana Sirimarco}

Mots-clés: Institution policière; Uniforme; Récit institutionnel.

Toute institution construit des récits qui la soutiennent. Ce sont des narratives qui mettent en scène des discours, des histoires de vie et des mise en valeur pour, ensuite, lui permettre de se définir en tant que groupe social et en tant qu'institution. Ce travail a pour but d'aborder les récits institutionnels les plus chers à la force policière : l'uniforme en tant qu' investiture. Si je propose d'aborder le symbole de l'uniforme de cette façon c'est parce que je crois qu'autour des symboles qu'il incarne, se construit une compréhension aussi bien de l'individu qui le porte que du groupe auquel il appartient. C'est dans la transmission de ces compréhensions que réside le sens du récit, capable de fonctionner comme une image de pensée et d'orienter le discours vers une direction spécifique. Pénétrer les sentiments, qui tournent dans une espèce de tourbillon et qui se sédimente autour de la figure de l'uniforme est une manière de commencer à thématiser les modes concrets par lesquels l'institution et les individus pensent à propos d'eux-mêmes. 